\title{
Physico-chemical indicators of inter-specific variability in vibration damping of wood
}

\author{
Iris BRÉMAUd ${ }^{1,2 *}$, Kazuya MinATO ${ }^{2}$, Patrick LANGBOUR $^{3}$, Bernard THIBAUT $^{4}$ \\ ${ }^{1}$ Laboratoire de Mécanique et Génie Civil, CNRS, Université Montpellier 2, Place E. Bataillon, cc 048, 34095 Montpellier Cedex 5, France \\ ${ }^{2}$ Laboratory of Forest Resources Circulatory System, Graduate School of Life and Environmental Sciences, \\ Kyoto Prefectural University, Kyoto 606-8522, Japan \\ ${ }^{3}$ Production et valorisation des bois tropicaux et méditerranéens, CIRAD PERSYST Department, TA B40/16 BP 5035, \\ 34398 Montpellier Cedex 5, France \\ ${ }^{4}$ CNRS, UMR Ecologie des Forêts de Guyane, BP 316 - 97379 Kourou Cedex, French Guyana
}

(Received 2 November 2009; accepted 13 February 2010)

Keywords:

damping coefficient /

diversity of woods /

extractives /

physical properties /

vibrational properties

\begin{abstract}
- The vibration damping coefficient (tan $\delta$ ) of wood is an important property for acoustical uses, including musical instruments. Current difficulties in the availability of some of the preferred species call for diversification, but this comes up against the lack of systematic damping coefficient data.

- Keeping in mind the possible factors affecting tan $\delta$, could we predict its variations between species, by using indicators that are either easily measured and/or readily available for many species?

- Vibrational properties, equilibrium moisture content and colorimetric parameters were assessed on 94 wood types belonging to 76 species. Experimental results were then related to data on chemical contents and physical properties from the CIRAD database. The "standard" relationship between $\tan \delta$ and specific modulus of elasticity $\left(E^{\prime} / \rho\right)$ explained only half of the variations. Deviations from this trend were correlated to extractives content, yet effects were not directly quantitative. Damping deviations were also correlated to colour and moisture-related properties, especially so with fibre saturation point.

- By taking into account a combination of moisture-related properties, colour - or extractives content, and the "standard" relationship between tan $\delta$ and $\mathrm{E} / \rho$, we could propose simple predictive models which explain up to $89 \%$ of observed variations in tan $\delta$ between 48 species.
\end{abstract}

\section{INTRODUCTION}

Vibration damping, or the loss coefficient $(\tan \delta)$ of wood, is an important parameter for several "acoustical" applications. Different ranges of tan $\delta$ values are required depending on the considered end-uses. For example, in the case of different parts and families of musical instruments (e.g. Bucur, 2006; Wegst, 2006). A very low damping of wood is required for xylophones keys (Aramaki et al., 2007; Brémaud et al., 2008; Hase 1987), and is also believed to be important for modern violin bows (Brémaud and Poidevin, 2009; Matsunaga et al., 1996; Wegst et al., 2007). While woods for violin top plates are within the middle-low range of $\tan \delta$ for woods, and the reeds for clarinets have extremely high tan $\delta$ (Obataya and Norimoto, 1999). Instrument makers are currently facing supply concerns about the availability of several of the

*Corresponding author: iris_bremaud@hotmail.com traditionally preferred wood species in sufficient quantities and/or quality. A diversification in the usable species could help to overcome this situation, yet such an approach requires sufficient knowledge of the relevant material properties of potential "alternative" species. Unfortunately, though extensive databases exist concerning the technological properties of woods, the data on inter-specific variability of damping coefficient are scattered and scarce.

For wood along the grain, vibrational properties $-\tan \delta$ and specific modulus of elasticity $\left(\mathrm{E}^{\prime} / \rho\right)$ - are primarily determined at the cell-wall level (Norimoto et al., 1986; Obataya et al., 2000). $E^{\prime} / \rho$ decreases, and tan $\delta$ increases, with increasing microfibril angle, resulting in these two properties being generally related (Ono and Norimoto, 1983; 1984). The loss coefficient, on the other hand, is also highly dependent on variations in chemical composition (e.g. Obataya et al., 2000). Notably, extractives, which are extremely variable between species both in their amount and in their nature, can 
modify tan $\delta$ by as much as a factor 2, either decreasing it (Brémaud et al. 2010; Matsunaga et al., 1999; Minato et al., 2010; Yano, 1994; Yano et al., 1995) or occasionally increasing it (Obataya and Norimoto, 1999; Yano, 1994). Such effects, however, have been established only for a few species. Extractives, on the other hand, are also known to affect other characteristics of wood, such as colour or moisture-related properties. Within a given species, colorimetric parameters can provide predictions of extractives content and/or of properties affected by these compounds, such as natural durability (Amusant et al., 2004; 2008; Gierlinger et al., 2004). Moreover, they represent rapid and non-destructive surface measurements. Between species, however, different chemical groups of extractives can have different optical properties. Concerning moisture-related properties, the presence of extractives in wood cell-walls can clearly diminish the equilibrium moisture content of wood, its fibre saturation point, and its volumetric shrinkage (Chafe, 1987; Hernandez, 2007 a, b, c; Skaar, 1988; Wangaard and Granados, 1967). The determination of these properties is time-consuming, but comparable data are available for many wood species.

The general objective of this work was to identify indicators that can be quickly measured, or that are available for many species, in order to estimate damping coefficients and overcome the lack of inter-specific data on this property. It was based on two hypotheses to be tested, namely: (i) that extractives might affect tan $\delta$ of a relatively large number of species; (ii) that physical properties which are known to be affected by extractives could indirectly reflect the presence of extractives able to modify damping. At the inter-specific level, these hypotheses are quite strong, as variations do not only concern the amount, but also the nature of extractives and thus their physico-chemical properties.

\section{MATERIALS AND METHODS}

\subsection{Materials}

Studied species included 4 groups chosen on different basis: to cover a wide range of (i) specific gravity and Young's modulus; (ii) fibre saturation point and volumetric shrinkage; (iii) extractive contents; and (iv) woods used or under trial for musical instrument-making. Selection for groups (i), (ii) and (iii) mostly relied on the CIRAD database of technological properties of tropical woods, and, when available, related material was obtained from the CIRAD wood workshop. Material for group (iv) was provided by several French instrument makers.

Total sampling included 76 species and covered 94 wood types (i.e. sapwood vs. heartwood for some species). Tropical and temperate hardwoods and softwoods represented, respectively, 65, 10 and 19 wood types. 1320 specimens of dimensions $12 \times 2 \times 150 \mathrm{~mm}^{3}(R \times T \times L)$ were cut from 257 initial lots of wood. All experiments (vibrational, physical and colorimetric), were run on the same specimens. An initial sampling of 70 wood types was first studied under given conditions, then a 2nd sampling of 24 wood types, used to check the robustness of inter-properties relations, was tested under slightly different experimental conditions (described below).

\subsection{Physical and colorimetric measurements}

Specimens were first dried, in order to reach equilibrium in adsorption. Drying was performed for $48 \mathrm{~h}$ in a dry oven set at $60{ }^{\circ} \mathrm{C}$ (to avoid drying damage or cracking of specimens, or degradation of non-volatile extractives). Residual moisture content was of $0.75 \pm 0.03 \%$ and was taken into account in results. Specimens were then stabilized for at least 3 weeks in a climatic chamber before measuring their "air-dry" specific gravity $(\rho)$ and equilibrium moisture content $(E M C)$. The 1 st sampling was conditioned in $\left(20 \pm 1{ }^{\circ} \mathrm{C}\right.$ and $\left.65 \pm 2 \% \mathrm{RH}\right)$ and the $2 \mathrm{nd}$ in $\left(20 \pm 1{ }^{\circ} \mathrm{C}\right.$ and $\left.60 \pm 2 \% \mathrm{RH}\right)$.

Colorimetric parameters were measured with a spectrocolorimeter (Datacolor Microflash 100) using CIE $10^{\circ}$ standard observer and illuminant $\mathrm{A}$ and a sensor head diameter of $8.7 \mathrm{~mm}$. Measurements were conducted in triplicate for each specimen. Data were collected in the CIELab system, where $L^{*}$ is lightness $(0=$ black, $100=$ white $), a^{*}$ is the green to red axis and $b^{*}$ is the blue to yellow axis. Results were analysed in CIELCh cylindrical coordinates, where chroma (or saturation, $\left.C^{*}=\sqrt{a^{* 2}+b^{* 2}}\right)$ denotes the distance to the grey axis, and hue angle $\left(h^{*}=\arctan \left(b^{*} / a^{*}\right)\right)$ is $0^{\circ}$ for red and $90^{\circ}$ for yellow. 1st sampling was measured within a week after specimen cutting, and 2 nd sampling after 8 to 10 months.

\subsection{Vibrational properties}

Vibrational properties were measured on $12 \times 2 \times 150 \mathrm{~mm}^{3}$ $(R \times T \times L)$ specimens after stabilization, using non-contact forced vibrations of free-free bars (e.g. Brémaud, 2006; Obataya et al., 2000). Specimens were supported by loose thin silk threads located at the nodes of the 1st mode of flexural vibrations. Vibrations were applied with an electro-magnet facing a thin iron plate glued to one end of the specimen and the displacement was measured at a belly of vibration by a non-contact sensor (laser or eddy current). A frequency scan allowed detection of the first resonant frequency (in bending) from which the specific modulus of elasticity $\left(E^{\prime} / \rho\right)$ was deduced according to the Euler-Bernouilli equation. The damping coefficient (tan $\delta$ ) was measured through logarithmic decrement of amplitude after stopping the excitation (at the resonance frequency). Measurement frequencies were in the range of 200-600 Hz. Triplicate measurements were made for each specimen and the mean error was $\leq 5 \%$.

\subsection{Data analysis and comparison with database values}

Data were averaged, first between specimens prepared from a given stock (or tree), then between stocks - when applicable. Relationships between mean properties per wood type were tested by simple Pearson's correlations (using Xlstat ${ }^{\circledR}$ ) and multiple linear regression models were tried out (using stepwise procedures in Statistica ${ }^{\circledR}$ ) for predicting damping variations.

Experimentally determined properties were set against other parameters collected from the CIRAD database, determined on the same species (or sometimes the same tree). 


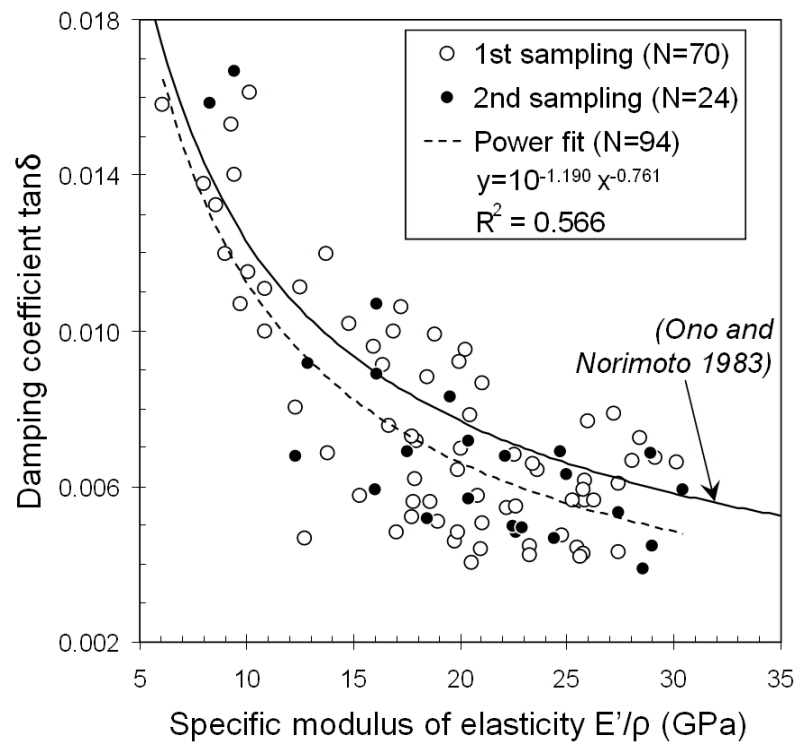

Figure 1. Means per wood types of damping coefficient and specific modulus of elasticity.

Physical-mechanical parameters included: air-dry specific gravity; Young's modulus ( $E$, measured by 3-point static bending and corrected for equivalent 4-point bending according to Brancheriau et al., 2002); fibre saturation point (FS P, determined by the intersection point of shrinkage) and volumetric shrinkage (VSh, from green to oven-dry). Chemical parameters included lignin (Klason), cellulose, alcohol-benzene and hot-water extractives content. Hemicellulose content was estimated by subtraction from the total.

\section{RESULTS AND DISCUSSION}

\subsection{Vibrational properties}

Over the 94 wood types (with specific gravities of 0.22 to 1.31 ), the mean values of tan $\delta$ and of $E^{\prime} / \rho$ were related (Fig. 1) in a way very similar to the "standard" relationship reported by Ono and Norimoto $(1983 ; 1984)$. This relationship, however, explained only about half $(57 \%)$ of the variations in $\tan \delta$. Therefore, $E^{\prime} / \rho$ was not sufficient to predict the damping coefficient. The strength of association that we observed between $\tan \delta$ and $E^{\prime} / \rho$ is similar to that obtained by Ono and Norimoto (although in their 1983 and 1984 articles the relationship was presented on a double-logarithmic scale in which the apparent $R^{2}$ was higher). As, however, both properties are nevertheless linked to each other, in order to specifically describe damping variations, we needed some additional parameters to de-correlate it from specific modulus of elasticity. This could be achieved by using either the specific loss modulus $E^{\prime \prime} / \rho$ (Eq. (1)), which is a mechanical property in itself, or the deviation from the standard tan $\delta-E^{\prime} / \rho$ relationship (equivalent to a "normalized damping") which we will note $\Delta \tan \delta$
(Eq. (2)) and is simply a statistical indicator,

$$
\begin{aligned}
E^{\prime \prime} / \rho & =\tan \delta \times\left(E^{\prime} / \rho\right) \\
\Delta \tan \delta & =100 \times \frac{\tan \delta_{i}-\tan \delta_{s}}{\tan \delta_{s}}
\end{aligned}
$$

with

$$
\tan \delta_{s}=10^{-A} \times\left(E^{\prime} / \rho\right)^{-B}
$$

and $\tan \delta_{i}$ is the average measured value on a given wood type.

Equation (3) is the standard trend reported by (Ono and Norimoto, 1983), where the values of constants are $\mathrm{A}=1.230$ and $\mathrm{B}=0.680$. We found nearly identical constants $(\mathrm{A}=$ $1.231, \mathrm{~B}=0.677$ ) for specimens with low extractives' content $(\mathrm{N}=221)$, for which the relationship was also stronger than the general one. The relationship for specimens with high extractives' content followed a similar and quite parallel curve, but shifted towards low tan $\delta$ values and with more dispersion.

\subsection{Indicators measured on the same wood pieces}

The damping coefficient (tan $\delta$ ) was correlated, by order of importance, to: $E^{\prime} / \rho \geq \Delta \tan \delta \geq L^{*} \geq h^{*} \approx E M C \geq \rho$ (Tab. I). The strength of the relationships between tan $\delta$ and $E^{\prime} / \rho$ or $\Delta \tan \delta$ was independent of sample number and measurement conditions. Considering our goal to de-correlate tan $\delta$ from $E^{\prime} / \rho$, the specific loss modulus $\left(E^{\prime \prime} / \rho\right)$ remained correlated to $E^{\prime} / \rho$, and was a poor descriptor of $\tan \delta$. Conversely, "normalized damping" $(\Delta \tan \delta)$ efficiently described variations in $\tan \delta$, while not being linked to $E^{\prime} / \rho$ at all.

$\Delta \tan \delta$ showed clear positive links with moisture content and colorimetric parameters, with higher correlation coefficients than obtained directly with tan $\delta$. Incidentally, specific gravity appeared related to $\Delta \tan \delta$ and $\tan \delta$, while the latter is theoretically independent of $\rho$ (Norimoto et al., 1986; Obataya et al., 2000). This is probably due to denser woods containing more extractives.

Correlations between $\tan \delta$ or $\Delta \tan \delta$ and physical parameters $E M C, L^{*}$ and $h^{*}$ were weaker for the sum of 1 st and 2 nd samplings, reflecting the different testing conditions. Though, they remained significant at a probability level of 0.001, thus indicating that they were linked in a sufficiently strong manner to bypass moderate experimental disparities.

\subsubsection{Colorimetric parameters}

Lightness and hue were relatively good indicators of other properties (Tab. I). Redness $\left(a^{*}\right)$, yellowness $\left(b^{*}\right)$ and chroma $\left(C^{*}\right)$, on the other hand, were useless as indicators at the interspecific level. This was due to the fact that the "amount" of colour was dependent upon lightness in a highly nonlinear way: $C^{*}, a^{*}$ and $b^{*}$ increased strongly up to an $L^{*}$ of circa 55, then decreased when "light woods" became lighter. Conversely, $h^{*}$ changed in a more linear fashion. Our observations coincided very closely with those of Nishino et al. (1998). $L^{*}$ and $h^{*}$ respectively explained $57 \%$ and $53 \%$ of 
Table I. Pearson correlation matrix between physical and vibrational properties (above-diagonal for total sampling, under-diagonal 1st sampling). Correlations in bold are significant at $P<0.001$; bold italic: $P<0.01$; italic: $P<0.05$.

\begin{tabular}{cccccccccccccc}
\hline 1 st sampling $(N=70)$ & $\rho$ & 0.24 & $\mathbf{- 0 . 4 6}$ & $\mathbf{- 0 . 3 5}$ & $\mathbf{- 0 . 4 9}$ & $\mathbf{- 0 . 3 6}$ & $\mathbf{- 0 . 7 1}$ & - & $\mathbf{- 0 . 3 8}$ & $-\mathbf{0 . 2 8}$ & $\mathbf{- 0 . 5 7}$ & 1 st +2 nd samplings $(N=94)$ \\
& $\mathbf{0 . 3 6}$ & $E^{\prime} / \rho$ & $\mathbf{- 0 . 7 3}$ & $\mathbf{0 . 4 0}$ & - & - & - & - & - & - & - & \\
& $\mathbf{- 0 . 5 6}$ & $\mathbf{- 0 . 7 3}$ & $\tan \delta$ & 0.25 & $\mathbf{0 . 6 8}$ & $\mathbf{0 . 4 5}$ & $\mathbf{0 . 5 4}$ & - & 0.22 & - & $\mathbf{0 . 4 8}$ & \\
& -0.30 & $\mathbf{0 . 4 2}$ & 0.24 & $E^{\prime \prime} / \rho$ & $\mathbf{0 . 8 8}$ & $\mathbf{0 . 4 6}$ & $\mathbf{0 . 5 8}$ & - & $\mathbf{0 . 2 8}$ & 0.21 & $\mathbf{0 . 4 8}$ \\
& $\mathbf{- 0 . 5 0}$ & - & $\mathbf{0 . 6 6}$ & $\mathbf{0 . 8 9}$ & $\Delta \tan \delta$ & $\mathbf{0 . 5 7}$ & $\mathbf{0 . 7 0}$ & - & $\mathbf{0 . 3 1}$ & 0.22 & $\mathbf{0 . 5 9}$ \\
& $\mathbf{- 0 . 4 7}$ & - & $\mathbf{0 . 6 0}$ & $\mathbf{0 . 5 0}$ & $\mathbf{0 . 6 7}$ & EMC & $\mathbf{0 . 5 6}$ & -0.21 & 0.21 & - & $\mathbf{0 . 4 5}$ & \\
& $\mathbf{- 0 . 7 1}$ & - & $\mathbf{0 . 6 5}$ & $\mathbf{0 . 5 4}$ & $\mathbf{0 . 7 2}$ & $\mathbf{0 . 6 9}$ & $L^{*}$ & - & $\mathbf{0 . 6 7}$ & $\mathbf{0 . 5 4}$ & $\mathbf{0 . 8 3}$ & \\
& - & - & - & - & - & -0.26 & - & $a^{*}$ & $\mathbf{0 . 6 5}$ & $\mathbf{0 . 8 0}$ & - & \\
& $\mathbf{- 0 . 4 1}$ & - & 0.28 & 0.25 & $\mathbf{0 . 3 2}$ & 0.26 & $\mathbf{0 . 6 7}$ & $\mathbf{0 . 6 6}$ & $b^{*}$ & $\mathbf{0 . 9 6}$ & $\mathbf{0 . 6 5}$ & \\
& $\mathbf{- 0 . 3 4}$ & - & - & - & - & - & $\mathbf{0 . 5 4}$ & $\mathbf{0 . 8 1}$ & $\mathbf{0 . 9 7}$ & $C^{*}$ & $\mathbf{0 . 4 3}$ & \\
& $\mathbf{- 0 . 5 8}$ & - & $\mathbf{0 . 5 8}$ & $\mathbf{0 . 4 8}$ & $\mathbf{0 . 6 5}$ & $\mathbf{0 . 5 8}$ & $\mathbf{0 . 8 5}$ & - & $\mathbf{0 . 6 6}$ & $\mathbf{0 . 4 7}$ & $h^{*}$ & \\
\hline
\end{tabular}
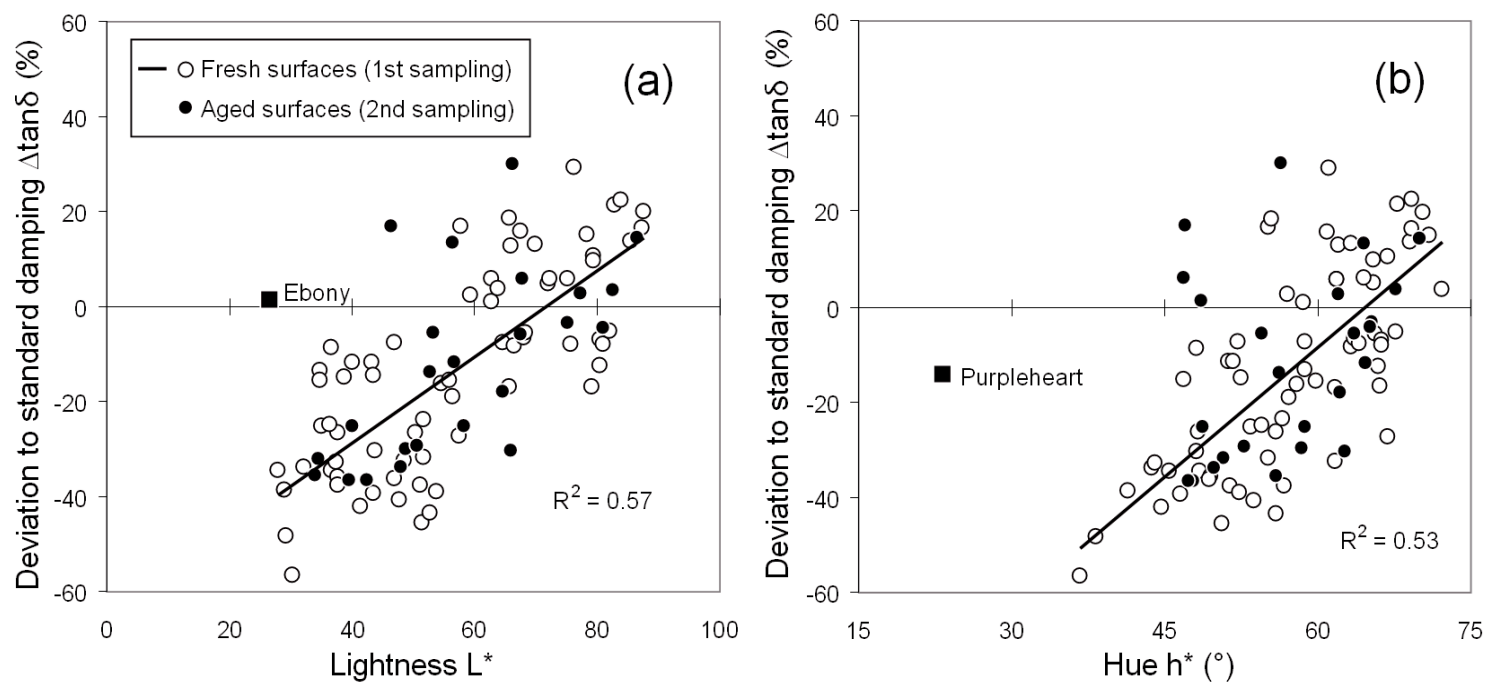

Figure 2. Relation between normalized damping $(\Delta \tan \delta)$ and colorimetric parameters $L^{*}$ (lightness, a) and $h^{*}$ (hue, b). Squares are outliers (ebony, purpleheart).

$\Delta$ tan $\delta$ variations (Fig. 2) on the1st sampling (colour measured on freshly cut wood). These relations were sufficiently robust, as the results on the 2 nd sampling (measurements on aged surfaces) conformed to the general trend.

When comparing highly different wood types, $L^{*}$ was the most efficient colorimetric indicator. In studies based on a single genus or species however, where the range in lightness and the nature of extractives are more focused, the colour parameter best related to extractives and/or properties is often the hue (Amusant et al., 2004; 2008; Gierlinger et al., 2004; Matsunaga et al., 1996). Colour could provide useful and fast to measure indicators; at the interspecific level however, it reflects both some quantitative and qualitative chemical variations.

\subsubsection{Equilibrium moisture content}

The $E M C$ was positively correlated to $\Delta \tan \delta$, yet it was, as an indicator, more sensitive than $L^{*}$ to changes in experimental conditions: it described half of the variations in $\Delta \tan \delta$ between the 70 wood types tested in $65 \%$ RH (Fig. 3), but only $37 \%$

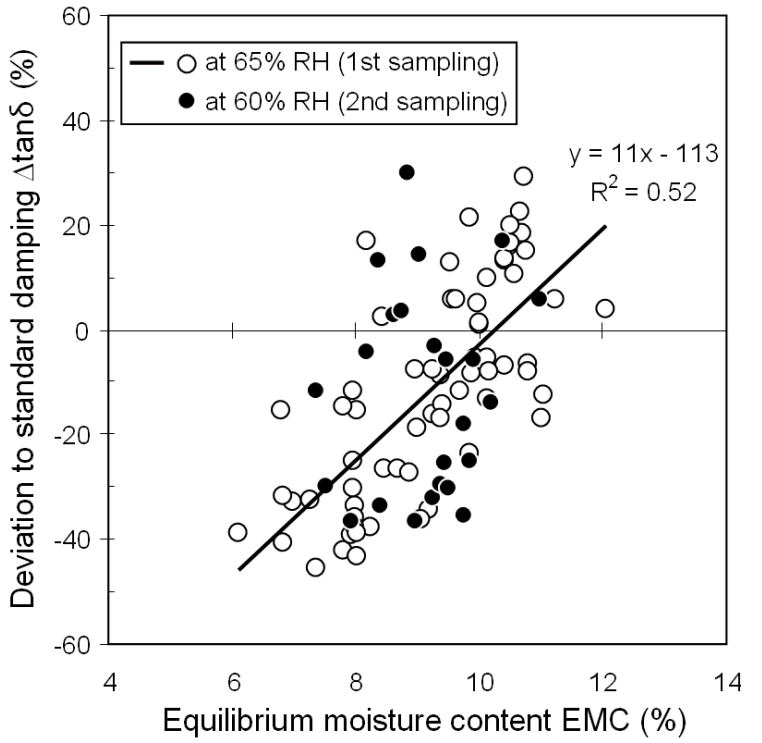

Figure 3. Relation between normalized damping and equilibrium moisture content. 

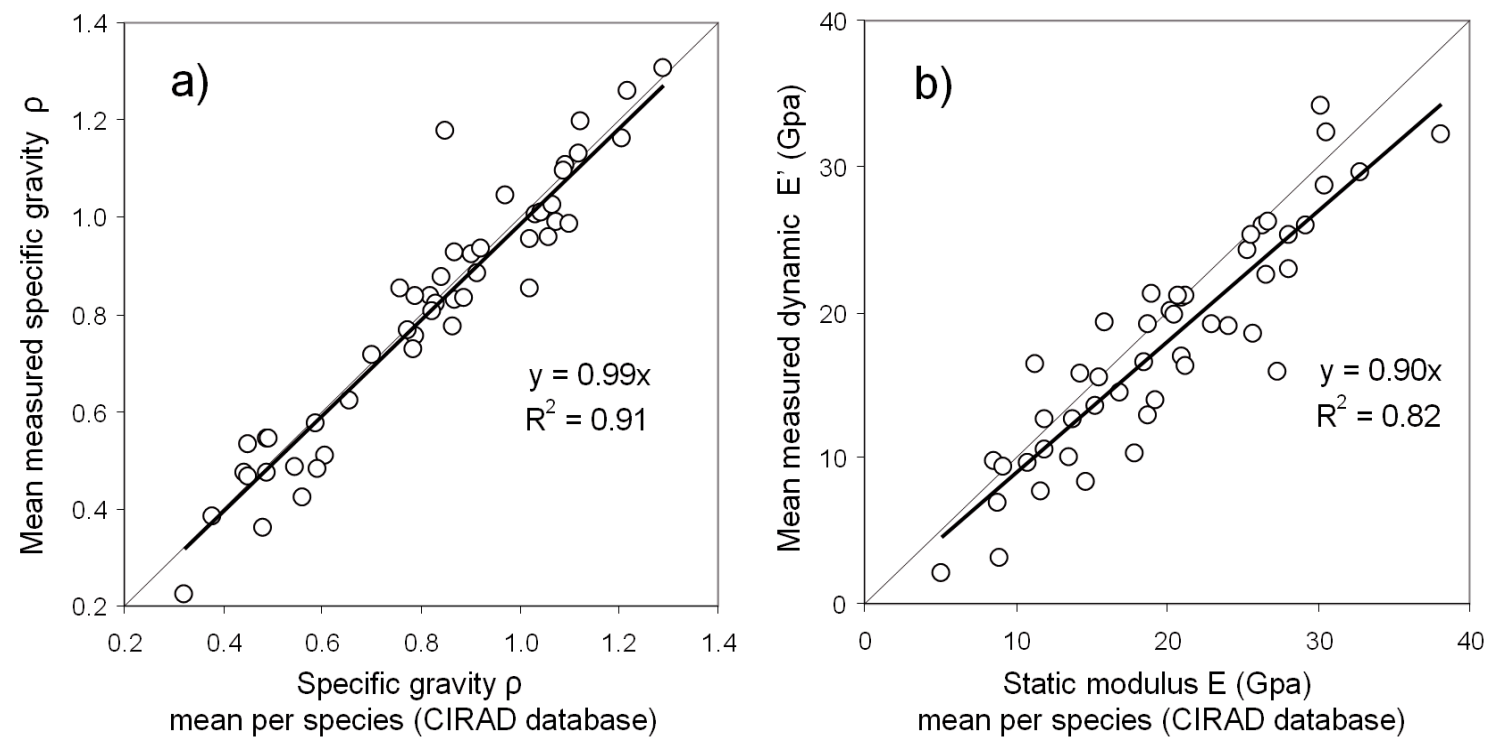

Figure 4. Comparison of mean properties measured on a limited sampling, with means per species (obtained on several trees and locations within trees) in CIRAD database. (a) Specific gravity; (b) Young's modulus.

when comparing them with 24 additional wood types tested in $60 \%$ RH.

The relationships between damping and moisture content reflect combined physical phenomena. On one hand, lower than average $E M C$ (under given conditions) may reflect a high content of extractives - either "neutral" or even hydrophobic (Hernandez, 2007a; Wangaard and Granados, 1967). On the other hand, the vibrational properties of wood are moisturedependent (Obataya et al., 1998). On a single wood type tested at different RHs, a change from circa $7 \%$ to $11 \%$ EMC would decrease $E^{\prime} / \rho$ by less than $10 \%$, and increase tan $\delta$ by approximately 20-25\% (Obataya et al., 1998; 2001), resulting in a maximum of $20 \%$ absolute increase in $\Delta \tan \delta$. This is much smaller than the total span $(-45 \%$ to $+30 \%)$ of $\Delta \tan \delta$ between species and wood types. Thus, the global relationship between $E M C$ and $\triangle \tan \delta$ expressed both: (i) the physical effects of moisture on vibrational properties, which would explain about one third of inter-specific variations; and (ii) the differences in chemical content and/or nature, accounting for the remaining variations. The high residual dispersion, however, suggests that there is not a single mechanism affecting simultaneously EMC and vibration damping, as effects were species-dependant.

\subsection{Indicators from previous tests on the same species}

Considering our goal of identifying damping indicators for the many species lesser-known for this property, existing databases of wood properties appeared to be the most appropriate tool. Our results, obtained on a moderate number of specimens for each species, are related below to chemical and physical data from the CIRAD database. Concerning specific gravity, a property common to the two sets of data, values from a few individuals were very consistent with those
Table II. Pearson's correlation coefficients between chemical contents and vibrational and physical properties (mean per species, hardwoods).

\begin{tabular}{lcccccc}
\hline$N=25$ & $\mathrm{AB}$ & $\mathrm{W}$ & $\mathrm{AB}+\mathrm{W}$ & $\mathrm{C}_{\mathrm{PC}}$ & $\mathrm{L}_{\mathrm{PC}}$ & $\mathrm{HC}_{\mathrm{PC}}$ \\
\hline$E^{\prime} / \rho$ & -0.2 & -0.4 & -0.3 & 0.2 & -0.3 & 0.0 \\
$\tan \delta$ & -0.4 & $\mathbf{0 . 5 3}$ & -0.3 & -0.3 & 0.1 & 0.2 \\
$E^{\prime \prime} / \rho$ & $\mathbf{- 0 . 7 3}$ & 0.2 & $\mathbf{- 0 . 7 1}$ & -0.1 & -0.1 & 0.2 \\
$\Delta \tan \delta$ & $\mathbf{- 0 . 7 2}$ & 0.4 & $\mathbf{- 0 . 6 6}$ & -0.2 & -0.1 & 0.2 \\
$E M C$ & $\mathbf{- 0 . 6 5}$ & 0.2 & $\mathbf{- 0 . 6 3}$ & 0.1 & -0.1 & 0.2 \\
$F S P$ & $\mathbf{- 0 . 6 6}$ & 0.1 & $\mathbf{- 0 . 6 4}$ & -0.2 & 0.1 & 0.2 \\
$V S h$ & $\mathbf{- 0 . 5 7}$ & -0.3 & $\mathbf{- 0 . 6 4}$ & 0.0 & 0.3 & -0.2 \\
$\Delta V S h$ & $\mathbf{- 0 . 7 3}$ & 0.0 & $\mathbf{- 0 . 7 5}$ & 0.0 & 0.0 & 0.1 \\
\hline
\end{tabular}

$\mathrm{AB}$ : ethanol-benzene and $\mathrm{W}$ : hot water, extractives content. $\mathrm{C}_{\mathrm{PC}}, \mathrm{L}_{\mathrm{PC}}$ and $\mathrm{HC}_{\mathrm{PC}}$ : cellulose, lignin and hemicelluloses proportions. FSP: Fibre saturation point, VSh: Volumetric shrinkage.

from the database, representing several trees and locations within trees (Fig. 4a). The effect of intra-species variability was more noticeable on Young's modulus, although there was still circa $80 \%$ correspondence (Fig. 4b). Measured modulus values were on average $10 \%$ lower than those from the database, which can be partly explained by the small-sized specimens for vibration tests being sensitive to local variations in grain angle (i.e. species with interlocked grain), and partly by methodological effects (including the systematic corrective factor from 3- to 4- points static bending applied to database values).

\subsubsection{Relationships to chemical contents}

Over the 25 tropical hardwoods with chemical content data, the most obvious correlations (Tab. II) were negative links 


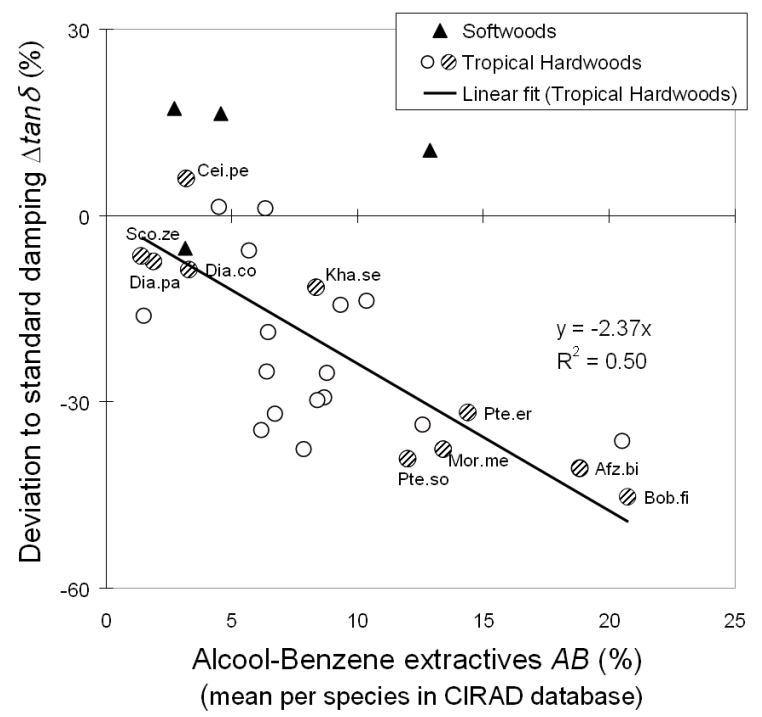

Figure 5. Relation between normalized damping and mean alcoolbenzene extractives content per species. Dashed symbols $=$ species for which the same trees were studied for damping and for extractives.

between Alcool-benzene extractives (AB) and loss parameters $\left(E^{\prime \prime} / \rho\right.$ and $\left.\Delta \tan \delta\right)$ or moisture-related properties. No clear correlations appeared with water extracts. In this case, colorimetric parameters were not correlated with chemical content, partly because most of these 25 species were "dark" woods. This also recalled the fact that, between different species, colour variations tend to reflect the nature of extracts rather than their global amount.

Any potential effects of primary components (cellulose, lignins and hemicelluloses) were apparently smaller than, and thus masked by, those of the important variations in extractives content.

The mean $\mathrm{AB}$ extractive content per species explained approximately $50 \%$ of the variations in normalized damping $\Delta \tan \delta$ for hardwoods (Fig. 5). The number of softwoods was too low for analysis, but these species appeared to behave differently. The hardwood relationship reflected that a rather high extractive content was a necessary, but not sufficient condition for wood to display a lower than standard damping. There was a clear general tendency of damping to decrease with higher extractives content, but, especially for medium $\mathrm{AB}$ contents (5-10\%), the effects were species-dependent and thus probably governed by the nature of the compounds. Extractives content, on the other hand, is known to be variable within species (e.g. Hillis, 1987). When vibrational and chemical data had been obtained for the same trees (Fig. 6), the relationship became much stronger $\left(R^{2}=80 \%\right)$. This reflects both the better correspondence of material, and the fact that variations between trees of a given species should be more quantitative than those between different species, where the nature of compounds varies together with their amounts. Both tendencies, however, were comparable, with, in average, a $\Delta \tan \delta$ decrease of circa $2 \%$ per $1 \%$ of $\mathrm{AB}$ extracts.

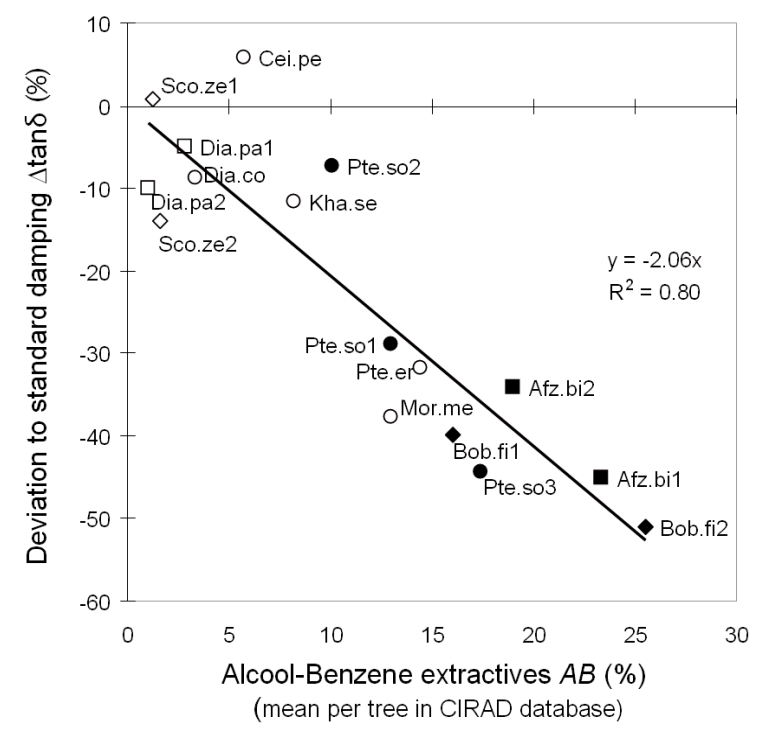

Figure 6. Relationship between $\Delta \tan \delta$ and $\mathrm{AB}$ extractives determined on the same trees (16 trees from 10 hardwood species).

Table III. Pearson's correlation coefficients between measured properties, and database values of fibre saturation point and volumetric shrinkage.

\begin{tabular}{lccc}
\hline$N=48$ & $F S P$ & $V S h$ & $\Delta V S h$ \\
\hline$\rho$ & $\mathbf{- 0 . 5 6}$ & 0.31 & $\mathbf{- 0 . 5 1}$ \\
$E^{\prime} / \rho$ & -0.13 & $\mathbf{0 . 4 7}$ & 0.12 \\
$\tan \delta$ & $\mathbf{0 . 7 1}$ & -0.01 & $\mathbf{0 . 5 3}$ \\
$E^{\prime \prime} / \rho$ & $\mathbf{0 . 7 2}$ & $\mathbf{0 . 4 8}$ & $\mathbf{0 . 7 6}$ \\
$\Delta \tan \delta$ & $\mathbf{0 . 8 4}$ & 0.36 & $\mathbf{0 . 8 0}$ \\
$L^{*}$ & $\mathbf{0 . 7 0}$ & 0.11 & $\mathbf{0 . 6 9}$ \\
$E M C$ & $\mathbf{0 . 7 3}$ & $\mathbf{0 . 4 3}$ & $\mathbf{0 . 7 9}$ \\
\hline
\end{tabular}

\subsubsection{Fibre saturation point and volumetric shrinkage}

The volumetric shrinkage of studied species was barely related to specific gravity, in contrast to the general case. Simple regression analyses on tropical woods give a rough approximation $V S h \approx(12 \times \rho)+4$ (e.g. Skaar, 1988) which was corroborated by simple analyses conducted on a thousand species from the CIRAD database. Here we called $\triangle V S h$ the deviation of actual shrinkage from this general trend.

Both FSP and $\Delta V S h$ were strongly negatively affected by $\mathrm{AB}$ extractives content (Tab. II), which is consistent with previous work (Chafe, 1987; Hernandez, 2007b; 2007c; Wangaard and Granados, 1967). In turn, FSP and $\Delta$ VSh were good indicators of damping parameters (Tab. III).

Between 48 species, FSP variations explained $70 \%$ of damping deviations from standard relationships (Fig. 7). This relationship was stronger than that of $\Delta \tan \delta$ with measured $E M C$ : FSP could better reflect extractives content, as extractives effects on moisture content are greatest over the higher range of relative humidity (Wangaard and Granados, 1967). The relationship of $\Delta \tan \delta$ to shrinkage deviations was nearly as strong as that with FSP, but was redundant with it. 
Table IV. Multiple regression equations of the deviations ( $\Delta \tan \delta)$ from standard damping as a function of colour, moisture-related properties and extractives content. Numbers in brackets are beta coefficients.

\begin{tabular}{|c|c|c|c|c|c|c|}
\hline Equation & & & & & $R^{2}$ & Standard error \\
\hline \multicolumn{7}{|c|}{ Model 1 (Indicators measured on same specimens, in identical conditions, $N=70$ ) } \\
\hline$\Delta \tan \delta=$ & -103 & $\begin{array}{c}+6.7 \text { EMC } \\
(0.42)\end{array}$ & $\begin{array}{c}+0.49 L^{*} \\
(0.41)\end{array}$ & & 0.60 & 13.4 \\
\hline $\begin{array}{l}\text { Model } 2 \\
\Delta \tan \delta=\end{array}$ & $\begin{array}{c}d+d a \\
-75\end{array}$ & $\begin{array}{c}\text { dicators, } N= \\
+2.3 \text { FSP } \\
(0.64)\end{array}$ & $\begin{array}{c}+0.62 L^{*} \\
(0.49)\end{array}$ & $\begin{array}{c}-0.62 h^{*} \\
(-0.28)\end{array}$ & 0.76 & 10.1 \\
\hline \multicolumn{7}{|c|}{ Model 3 (Database indicators, $N=25$ ) } \\
\hline$\Delta \tan \delta=$ & -53 & $\begin{array}{c}-1.1 \mathrm{AB} \\
(-0.43)\end{array}$ & $\begin{array}{c}+1.7 \text { FSP } \\
(0.43)\end{array}$ & & 0.62 & 9.1 \\
\hline
\end{tabular}

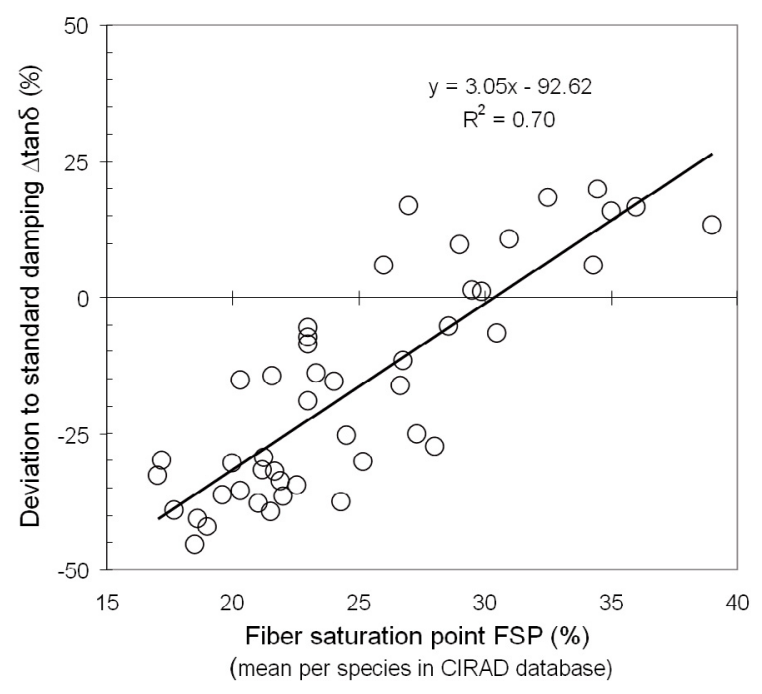

Figure 7. Relation between normalized damping and fibre saturation point.

The relationship between FSP and $\Delta \tan \delta$ was sufficiently robust to give consistent indicators of inter-specific variability, even though the samplings were different. Moisture-related properties could indirectly reflect, not only extractives contents, but also some additional information, as these properties should mostly be affected by extractives located in the cellwalls (Chafe, 1987; Hernandez, 2007a; 2007b; 2007c). Hygroscopic stabilisation and modification of vibrational properties, on the other hand, could imply different mechanisms of action of extractives, which could explain the residual dispersion in the FSP- $\Delta \tan \delta$ relationship, together with sampling effects.

\subsection{Predictions of damping coefficient}

Multiple regression analyses were applied in order to determine which combination of indicators better described the deviations of damping from the standard relationship. Three sets of independent variables were used for building multi-linear models (Tab. IV) by stepwise procedures, where the threshold for variables to enter the model was set at a probability level of $1 \%$. The general figure indicated that actual variations in $\Delta$ tand were associated with moisture-related properties - FSP

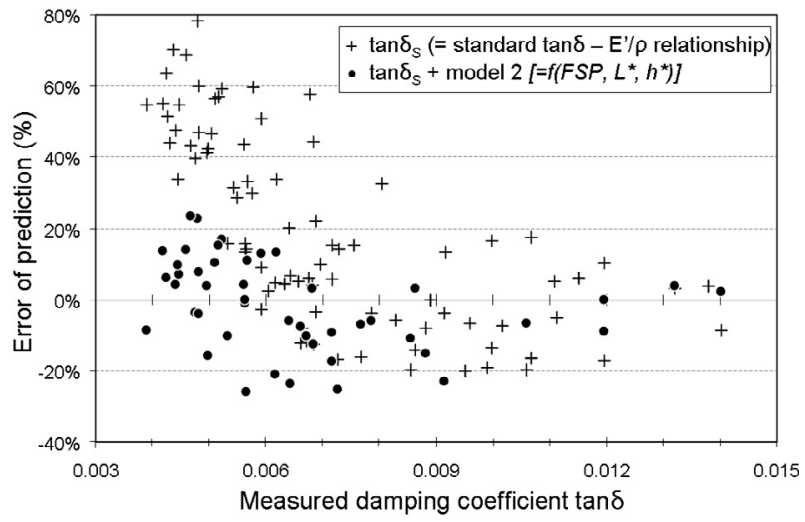

Figure 8. Error of prediction of damping coefficient as a function of actual tan $\delta$ values.

being a better indicator than $E M C$ at $65 \% \mathrm{RH}$ - in combination with colour lightness - which was replaced by extractives content when data were available. Though, it would be useful to broaden the sampling with chemical data to more differently coloured woods.

The damping coefficient ( $\tan \delta$ ) can be estimated using these models of $\Delta \tan \delta$ in combination with the standard $\tan \delta-E^{\prime} / \rho$ relationships (Eq. (4)),

$$
\tan \delta_{p}=\tan \delta_{s} \times\left(1+\Delta \tan \delta_{p} / 100\right)
$$

where $\tan \delta_{p}$ is the predicted value, $\Delta \tan \delta_{p}$ corresponds to the equations in Table IV, and $\tan \delta_{s}$ corresponds to equation (3).

While the standard relationship failed to describe actual damping coefficients, particularly in their lower range (Fig. 8), the multi-variable predictions had a much reduced error in this low range of tan $\delta$. Predictions using model 2 explained $89 \%$ of inter-species variations in $\tan \delta$, with a prediction error that was $<20 \%$ for $85 \%$ of tested species (Fig. 8). Additionally, prediction was still relatively good when taking into account only $F S P$ and $E^{\prime} / \rho$, which could prove very useful for screening existing databases of physical properties that generally do not include colorimetric parameters.

\section{CONCLUSION}

This work aimed at identifying indicators, easily measured or readily available in existing databases, to estimate 
the vibration damping coefficient (tan $\delta)$ for the very many wood species for which this property is unknown. Results have shown that:

- The "standard" relationship between $\tan \delta$ and specific modulus of elasticity from the literature can be corroborated but only explains approximately half of inter-specific variations.

- Abnormally low tan $\delta$ is indeed associated with higher extractives content, and this completely masks any potential links with primary composition. This relationship, however, is species-dependent and is thus probably governed by the nature of compounds, and is quite sensitive to intraspecific variability.

- Damping deviations are related to wood colour (mostly to lightness and, to a lesser degree, to hue) which, at the inter-specific level, should reflect both some quantitative and qualitative chemical variations.

- Moisture-related properties also provide relatively good indicators of damping variations, fibre saturation point being the most efficient. These links should reflect both the direct effect of hygroscopicity on tan $\delta$, and indirectly those of extractives.

By taking into account a combination of moisture-related properties, colour - or extractives content, and the "standard" relation to $E^{\prime} / \rho$, we could propose simple predictive models which describe nearly $90 \%$ of inter-specific variations of damping coefficient. As these were established on a majority of tropical hardwoods, however, it would be useful to check their generalization to other categories.

Acknowledgements: The authors wish to thank C. Daigremont and S. Lotte in the CIRAD wood workshop, along with the instrument makers who provided wood material. This work was supported by a doctoral grant from CNRS in France and by a Post-Doctoral fellowship from the Japan Society for the Promotion of Science.

\section{REFERENCES}

Amusant N., Beauchêne J., Fournier M., Janin G., and Thévenon M.-F., 2004. Decay resistance in Dicorynia guianensis Amsh.: analysis of inter-tree and intra-tree variability and relations with wood colour. Ann. For. Sci. 61: 373-380.

Amusant N., Fournier M., and Beauchêne J., 2008. Colour and decay resistance and its relationships in Eperua grandiflora. Ann. For. Sci. 65: 806.

Aramaki M., Baillères H., Brancheriau L., Kronland-Martinet R., and Ystad S., 2007. Sound quality assessment of wood for xylophone bars. J. Acoust. Soc. Am. 121: 2407-2421.

Brancheriau L., Baillères H., and Guitard D., 2002. Comparison between modulus of elasticity values calculated using 3 and 4 point bending tests on wooden samples. Wood Sci. Technol. 36: 367-383.

Brémaud I., 2006. Diversité des bois utilisés ou utilisables en facture d'instruments de musique. Thèse de doctorat, Université Montpellier II, 302 p.

Brémaud I. and Poidevin N., 2009. Approches culturelles et mécaniques dans le choix des bois en facture: cas des archets anciens, 5th Conference on Interdisciplinary Musicology, CIM09, 26-29 Octobre 2009, Paris, France.

Brémaud I., Cabrolier P., Minato K., Gérard J., and Thibaut B., 2008. Vibrational properties of tropical woods with historical uses in musical instruments. COST IE0601+ESWM Conference "Wood science for the preservation of cultural heritage": Braga (Portugal), 5-7 November 2008.
Brémaud I., Amusant N., Minato K., Gril J., and Thibaut B., 2010. Effect of extractives on vibrational properties of African Padauk (Pterocarpus soyauxii Taub.). Wood Sci. Technol. Doi: 10.1007/s0026-010-0337-3

Bucur V. 2006. Acoustics of wood, Springer Series in Wood Science, Berlin Heidelberg New York, 393 p.

Chafe C., 1987. Collapse, volumetric shrinkage, specific gravity and extractives in Eucalyptus and others species, Part II: The influence of wood extractives. Wood Sci. Technol. 21: 27-41.

Gierlinger N., Jacques D., Grabner M., Wimmer R., Schwanninger M., Rozenberg P., and Pâques L.E., 2004. Colour of larch heartwood and relationships to extractives and brown-rot decay resistance. Trees 18: $102-108$.

Hase N., 1987. A comparison between acoustic physical factors of Honduras rosewood for marimbas and xylophones and a sensory evaluation of these instruments (in Japanese). Mokuzai Gakkaishi 33: 762-768.

Hernandez R.E., 2007a. Moisture sorption properties of hardwoods as affected by their extraneous substances, wood density, and interlocked grain. Wood Fiber Sci. 39: 132-145.

Hernandez R.E., 2007b. Effects of extraneous substances, wood density and interlocked grain on fiber saturation point of hardwoods. Wood Mat. Sci. Eng. 2: 45-53.

Hernandez R.E., 2007c. Swelling properties of hardwoods as affected by their extraneous substances, wood density and interlocked grain. Wood Fiber Sci. 39: 146-158.

Hillis W. E., 1987. Heartwood and tree exudates, Springer-Verlag, Berlin, $268 \mathrm{p}$.

Matsunaga M., Sugiyama M., Minato K., and Norimoto M., 1996. Physical and mechanical properties required for violin bow materials. Holzforschung 50: 511-517.

Matsunaga M., Minato K., and Nakatsubo F., 1999. Vibrational property changes of spruce wood by impregnation with water-soluble extractives of pernambuco (Guilandina echinata Spreng.). J. Wood Sci. 45: $470-474$.

Minato K., Konaka Y., Brémaud I., Suzuki S., and Obataya E., 2010. Extractives of muirapiranga (Brosimun sp.) and its effects on the vibrational properties of wood. J. Wood Sci. 56: 41-46.

Nishino Y., Janin G., Chanson B., Détienne P., Gril J., and Thibaut B., 1998. Colorimetry of wood specimens from French Guiana. J. Wood Sci. 44: 3-8.

Norimoto M., Tanaka F., Ohogama T., and Ikimune R., 1986. Specific dynamic Young's modulus and internal friction of wood in the longitudinal direction (in Japanese). Wood Res. Tech. Notes 22: 53-65.

Obataya E., Norimoto M., and Gril J., 1998. The effects of adsorbed water on dynamic mechanical properties of wood. Polymer 39: 3059-3064.

Obataya E. and Norimoto M., 1999. Acoustic properties of a reed (Arundo donax L.) used for the vibrating plate of a clarinet. J. Acoust. Soc. Am. 106: 1106-1110.

Obataya E., Ono T., and Norimoto M., 2000. Vibrational properties of wood along the grain. J. Mater. Sci. 35: 2993-3001.

Obataya E., Minato K., and Tomita B., 2001. Influence of moisture content on the vibrational properties of hematoxylin-impregnated wood. J. Wood Sci. 47: 317-321.

Ono T. and Norimoto M., 1983. Study on Young's modulus and internal friction of wood in relation to the evaluation of wood for musical instruments. Jpn. J. Appl. Phys. 22: 611-614.

Ono T. and Norimoto M., 1984. On physical criteria for the selection of wood for soundboards of musical instruments. Rheol. Acta 23: 652656.

Skaar C., 1988. Wood-water relations, Springer-Verlag, 279 p.

Wangaard F.F. and Granados L.A., 1967. The effect of extractives on water-vapor sorption by wood. Wood Sci. Technol. 1: 253-277.

Wegst U.G.K. (2006). Wood for sound. Am. J. Bot. 93: 1439-1448.

Wegst U.G.K., Oberhoff S., Weller M., and Ashby M.F., 2007. Materials for violin bows. Int. J. Mat. Res. 98: 1230-1237.

Yano H., 1994. The changes in the acoustic properties of Western Red Cedar due to methanol extraction. Holzforschung 48: 491-495.

Yano H., Kyou K., Furuta Y., and Kajita H., 1995. Acoustic properties of Brazilian rosewood used for guitar back plate (in Japanese). Mokuzai Gakkaishi 41: 17-24. 